\title{
Research on the selection of pipe materials for water supply and drainage
}

\author{
Xingya Wei* \\ College of Civil and Traffic Engineering, Shanghai Urban Construction Vocational College, Shanghai, 200438, China
}

\begin{abstract}
Municipal water supply and drainage project is one of the infrastructures that affects the planning of modern city construction. Therefore, it is required that the municipal water supply and drainage project can achieve economic, social and ecological benefits. As one of the basic elements of engineering project, the quality, performance and price of pipe materials have become a common concern in engineering construction. With the continuous development of modern science and technology, the type of water supply and drainage pipe has increased significantly. This paper briefly analyzes the properties, advantages and disadvantages, and application of common water supply and drainage pipes, hoping to provide some reference and help for the selection of pipe materials.
\end{abstract}

\section{Introduction}

With the development of China's modernization, people's living standards and needs have been greatly improved, and the importance of water supply and drainage to people's quality of life has been gradually recognized. People's pursuit of drinking water quality and natural water environment is gradually improving, which promotes the rapid development of water supply and drainage engineering.

Water pipe is an important part of water supply and drainage system. It is necessary to optimize the selection of pipe materials for water supply and drainage engineering, in order to improve the stability and economy of urban water supply and drainage system.

In the past water supply and drainage engineering projects, there are some defects in the quality and cost performance of traditional pipes, due to the limitations of process materials and manufacturing technology. With the innovation and development of modern technology, the emergence of new materials has brought new pipes for municipal water supply and drainage engineering.

Water pipes mainly went through various stages from traditional metal/concrete pipes to plastic pipes to composite materials pipes. In the continuous technical improvement, the performance of plastic and composite pipes proved to be more excellent, gradually replacing metal pipes in engineering application. In addition, more and more new pipes are being developed and applied in projects.

\section{Selection standard of pipe materials}

\subsection{Safe}

In the selection of pipes, it must be ensured that they are within the relevant national health standards. Otherwise, the pipeline may pollute the internal water, especially the drinking water. Some plastic pipes have additives and soluble metal elements in the production due to the need of processing, which may cause impact on people's health to a certain extent. The pipes can be sold only after the national safety testing and certification.

\subsection{Durable \& reliable}

The priority of water pipe selection is to have a certain mechanical strength under the specified temperature and pressure and not easy to be corroded by the flowing fluid, in order to ensure the normal and long-term use of the pipeline. The corrosion and leakage should be considered specially in the selection of pipes. If water seepage or leakage occurs due to the use of unqualified pipe, the harm will be quite great and it is difficult to carry out effective treatment. It is easy to cause the pollution of drinking water and even cause the group problem of people's water safety.

\subsection{Economic}

In the selection of pipes, the cost of installation and maintenance should be considered as well as the material price. For example, it needs high cost to install thin-walled copper tube although the price of pipe itself is not expensive. Besides, the selection range of pipe diameter is 
also different according to the different types of pipe materials. In order to expand interests and meet the needs of various customers, some enterprises increase the diameter type of water pipe, which affects the establishment of pipe standard to a certain extent.

\subsection{Convenient}

The convenience of pipe use includes the construction convenience and maintenance convenience. For example, when comparing the connection mode, steel pipe performs poorly since it needs a lot of on-site welding. Using the socket joint, cast iron pipe has certain advantages although its weight is greater. The much lighter PVC-U pipe is better which also uses the socket joint. Glass fiber reinforced plastic pipe and PE pipes also have advantages when using bonding. However, for designers and operators, the biggest advantage of steel pipes is that they can be opened on-site at almost anywhere as will.

\subsection{Environmental}

No matter what kind of pipe, it consumes a certain amount of resources and energy from processing, production, installation to operation. For example, it was found that the energy consumption of metal pipe was much higher than that of plastic pipe, especially when spraying or hot stretching process was selected. In addition, the internal surface roughness of the pipe will also affect the energy consumption.

\section{Traditional metal/concrete pipes}

\subsection{Cast iron pipe}

The wall of cast iron pipe is relatively thin, but its strength can fully meet actual demand, while the pressure resistance, impact resistance, earthquake resistance and fire resistance are all good. The cast iron pipe is not easy to produce corrosion in actual use, and the production cost and operation noise are low, so it is very suitable for buried pipeline laying. At present, cast iron pipe has been widely used in water supply and drainage engineering. However, the cast iron material is relatively brittle and itself weight is relatively large, which limits the popularization and application of cast iron pipe.

\subsection{Galvanized steel pipe}

For galvanized steel pipe, the rigidity is relatively large and the fire resistance is relatively strong, while the cost is relatively low. Therefore, the galvanized steel pipe has been widely used in fire water supply system. However, the weight of galvanized steel pipe is relatively large and it is very easy to corrosion. If used as water supply pipe for several years, a large amount of rust will be produced in the galvanized steel pipe, resulting in yellow water that not only pollutes the sanitary ware, but also be mixed with bacteria growing on the unsmoothed inner wall, which seriously endangers human health.

\subsection{Concrete \& Reinforced concrete pipes}

The production cost of concrete pipe or reinforced concrete pipe is relatively low. Thus, it has been widely used in urban water supply and drainage system. However, the weight of (reinforced) concrete pipe is relatively large, which leads to the difficulty in installation process. Moreover, the sealing performance of the joint position is poor, and leakage often occurs.

\section{New-type plastic pipes}

\subsection{Polypropylene-random (PPR) pipe}

PPR pipes are widely used in cold and hot water system inside buildings, mainly due to the following advantages. PPR pipe has excellent sanitary performance with no scale in using process. It has good pressure resistance performance and overall quality can be effectively guaranteed, resulting in a long service life. PPR pipe has excellent heat resistance, the maximum working temperature is $95^{\circ} \mathrm{C}$ and it can be used for a long time at $70^{\circ} \mathrm{C}$. PPR pipe has light weight and excellent welding performance, which makes easy installation and maintenance, leading to the energy saving and environmental protection.

\subsection{Polyethylene (PE) pipe}

According to the density, PE material can be divided into three types: low density, medium density and high density. In water supply and drainage engineering, high density PE pipe is used mostly. The single solid-wall PE pipe can be used for urban water supply, while double-wall corrugated/wound PE pipe can be used for drainage system. PE pipe is light in weight, good in flexibility and reliable in connection with each other, making it easy to be installed. PE pipe has good stress resistance, aging resistance and corrosion resistance, and good low temperature performance, leading to a long service life.

\subsection{Polybutene (PB) pipe}

PB pipe has good anti-aging, high temperature resistance and environmental protection performance. Therefore, it is widely used in water supply pipeline and heating pipe laying.

\subsection{Unplasticized Polyvinyl Chloride (UPVC) pipe}

UPVC pipe has beautiful appearance, light weight, low price, and good corrosion resistance. It is easy to cut off, convenient for installation and maintenance. The smooth inner surface makes good water tightness, good drainage performance and noise prevention performance. Therefore, UPVC pipe is mostly used for building drainage pipe. However, it is not good in temperature resistance performance. It has poor compressive strength and cannot be used in high-rise buildings. Besides, glue and other additives with high toxicity that used in 
processing and installing may cause potential safety risk.

\subsection{Acrylonitrile-Butadiene-Styrene plastic (ABS) pipe}

ABS pipe has good pressure resistance and acid/alkali resistance, at the same time has a strong impact resistance. ABS pipe has strong stability and is not easy to be affected by the changes of humidity and temperature. The applicable temperature range of $\mathrm{ABS}$ pipe is $-30^{\circ} \mathrm{C}$ to $70^{\circ} \mathrm{C}$, so it is suitable for low temperature environment in North China. In addition, it did not add toxic additives in the production process, leading to high healthy and environmental protection performance. However, the price of ABS pipe is relatively high and it cannot be widely used now.

\section{Composite materials pipes}

\subsection{Aluminum-plastic composite (PAP) pipe}

Discovered in the 1970s, polyethylene and welded aluminum pipe are compounded into PAP pipe by extrusion, presenting a three-layer structure from outside to inside. PAP pipe has the advantages of light weight, high mechanical strength, stable chemical properties, good corrosion resistance and non-toxic, so it can be used continuously for a long time. The polyethylene material used in the inner layer of PAP pipe makes it have very good smoothness, corresponding small friction coefficient and little noise in the process of water flow. In addition, there will be no scale and will not pollute the inside fluid.

\subsection{Steel-plastic composite (PSP) pipe}

As a new kind of composite pipe material, PSP pipe retains the rigidity and strength of traditional metal pipe, which is far better than plastic pipes and PAP pipe. PSP pipe has the characteristics of high mechanical strength, stable pressure bearing performance, well protection of water quality and long service life. PSP pipe can be connected by twisted wire, socket, flange, groove, welding, etc., showing fast and easy to install. As safer, more reliable, more economic and more environmental, PSP pipe can completely replace cast iron pipe and galvanized steel pipe in water supply field.

\section{Conclusions}

In order to ensure the safety and stability of water supply and drainage system and protect the health of users, the selection of pipe materials is very important. Reasonable selection of pipe material can also effectively save money and energy. Using traditional mental pipes, corrosion and water leakage are easy to occur, while new-type plastic pipes and composite materials pipes can solve the problems well. With the progress of science and technology, more pipes with strong comprehensive performance and good environmental protection performance will appear, which will bring great improvement to people's life.

\section{Acknowledgments}

Thanks to the financial support by the Morning Light Plan of Shanghai Educational Development Foundation of China (No.18CGB11).

\section{References}

1. Shi, W.X. (2020) Selection and construction practice of new pipe materials for municipal water supply and drainage. Intelligent City, (2): 31-32.

2. Jia, S.S. (2019) Analysis of common pipe materials for water supply and drainage. Shandong Industrial Technology, (2): 116.

3. Du, Y.Z. (2019) Selection and construction technology analysis of new water supply and drainage pipes. Construction Materials \& Decoration, (11): 18-19.

4. Zhang, X.C. (2019) Discussion on the selection and construction of new pipes for municipal water supply and drainage. Construction Materials \& Decoration, (26): 224-225.

5. Huang, C. (2019) Analysis of selection and construction technology of new water supply and drainage pipes. China Standardization, (6): 49-50.

6. Chen, S. (2019) Discussion on selection and construction technology of new water supply and drainage pipes. Modern Property Management, (6): 59. 